\section{Real-World Experience of Patients with Inoperable, Stage III Non-small-Cell Lung Cancer Treated with Durvalumab after Chemoradiotherapy: Indian Experience} \author{
Abhishek Mahajan² Amit Janu ${ }^{2}$ Kumar Prabhash \\ ${ }^{1}$ Department of Medical Oncology, Tata Memorial Centre, HBNI, \\ Mumbai, Maharashtra, India \\ 2Department of Radiology, Tata Memorial Centre, HBNI, Mumbai, \\ Maharashtra, India
}

Vanita Noronha ${ }^{1}$ Vikas T. Talreja ${ }^{1}$ Vijay Patil ${ }^{1}$ Amit Joshi ${ }^{1} \quad$ Nandini Menon ${ }^{1}$

\section{South Asian J Cancer 2020;9:180-182.}

Approximately $30 \%$ of patients with non-small-cell lung cancer (NSCLC) are diagnosed with Stage III disease, which is often unresectable. Historically, the standard of care has been platinum-based chemoradiotherapy (CRT), but outcomes have been poor. Durvalumab is a selective high-affinity, human immunoglobulin G1 monoclonal antibody that blocks programmed death-ligand 1 (PD-L1) binding to PD-1 and CD80. In the phase 3, PACIFIC trial of durvalumab versus placebo in patients with unresectable NSCLC without progressive disease after chemoradiation CRT, both primary end points progression-free survival (PFS) and overall survival(OS) were met and significantly improved with durvalumab (hazard ratio [HR] for PFS, 0.52; 95\% confidence interval [CI]: 0.42-0.65; $p<0.001$; HR for OS, 0.68 ; 99.73\% CI: 0.47-0.997; $p=0.0025$ ) with similar safety profiles between treatments. ${ }^{1}$ There are limited data from India for durvalumab use in NSCLC. We present initial experience for its use in our patients.

The details of these patients were obtained from the prospective lung cancer audit database that is maintained in the department of medical oncology. It included 15 NSCLC patients who have received durvalumab between March 2018 and March 2019. All eligible patients were adults with histologically or cytologically documented unresectable, Stage III NSCLC, regardless of tumor PD-L1 expression, which have not progressed after definitive CRT. Patients received durvalumab (10 mg/kg intravenously) every 2 weeks. We collected the demographic data, date of starting durvalumab, date of disease progression, date and reason for stopping or
Address for correspondence Kumar Prabhash, MBBS, MD, DM, Department of Medical Oncology, Tata Memorial Centre, HBNI, Mumbai, Maharashtra, India (e-mail: kumarprabhashtmh@gmail.com). interrupting durvalumab, date of death, response to previous treatment and durvalumab, and side effects. Data were collected with grading as per the Common Terminology Criteria for Adverse Events (version 4.03). Descriptive statistics were performed for analyzing demographic data, while PFS and OS were analyzed by plotting Kaplan-Meier curve and compared by log-rank test appropriately. ${ }^{2}$ - Tables 1 and 2 tabulate baseline characteristics and side effects of durvalumab, respectively. The mean PFS in our study was 8.5 months (range: 5.5-11.6 months) ( $=$ Fig. 1). Of these 15 patients, six has progressive disease and none of the patients have died

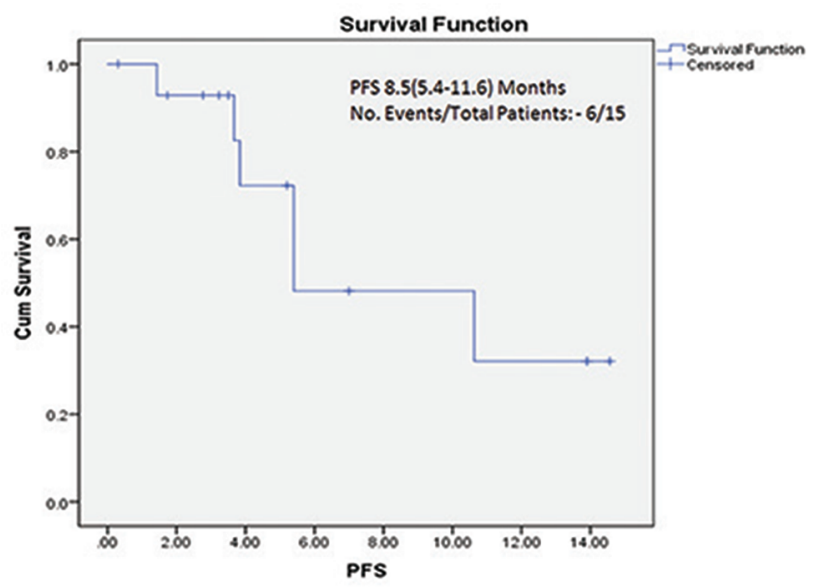

Fig. 1 Progression-free survival in patients on durvalumab.
How to cite this article: Noronha V, Talreja VT. Patil V. Joshi A. Menon N. Mahajan A. Janu A. Prabhash K. Real-World Experience of Patients with Inoperable, Stage III Non-small-Cell Lung Cancer Treated with Durvalumab after Chemoradiotherapy: Indian Experience. South Asian J Cancer 2020;9(3):180-182.

DOI https://doi.org/10.1055/s-0040-1721177 ISSN 2278-330X. (c) 2020. Medlntel Services Pvt Ltd.

This is an open access article published by Thieme under the terms of the Creative Commons Attribution-NonDerivative-NonCommercial-License, permitting copying and reproduction so long as the original work is given appropriate credit. Contents may not be used for commercial purposes, or adapted, remixed, transformed or built upon. (https://creativecommons.org/licenses/by-nc-nd/4.0/)

Thieme Medical and Scientific Publishers Pvt. Ltd., A-12, 2nd Floor, Sector 2, Noida-201301 UP, India 
Table 1 Baseline characteristics of patients treated with durvalumab $(n=15)$

\begin{tabular}{|c|c|}
\hline Demographic & $n(\%)$ \\
\hline Median age (y) (range) & $61(36-75)$ \\
\hline \multicolumn{2}{|l|}{ Gender } \\
\hline Female & $5(33.3)$ \\
\hline Male & $10(66.7)$ \\
\hline \multicolumn{2}{|l|}{ History of smoking/tobacco use } \\
\hline Yes & $10(66.7)$ \\
\hline No & $5(33.3)$ \\
\hline \multicolumn{2}{|l|}{ Histopathology } \\
\hline Adenocarcinoma & $8(53.3)$ \\
\hline Squamous carcinoma & $4(26.7)$ \\
\hline Poorly differentiated & $3(20)$ \\
\hline \multicolumn{2}{|l|}{ EGFR status } \\
\hline Wild & $12(80)$ \\
\hline Exon 19 del & $1(6.7)$ \\
\hline Exon 21 L858R mutation & $2(13.3)$ \\
\hline \multicolumn{2}{|l|}{ Other mutations } \\
\hline ALK & $1(6.7)$ \\
\hline ROS & $1(6.7)$ \\
\hline \multicolumn{2}{|l|}{ Stage of lung cancer $\left(\text { TNM } 8^{\text {th }}\right)^{3}$} \\
\hline IIIA & $5(33.3)$ \\
\hline IIIB & $5(33.3)$ \\
\hline IIIC & $5(33.3)$ \\
\hline \multicolumn{2}{|c|}{ Best responses post-CRT (PET-CT) } \\
\hline CMR & $1(6.7)$ \\
\hline PR & $7(46.7)$ \\
\hline SD & $7(46.7)$ \\
\hline Baseline CEA levels (ng/ml) & $54(4-242)$ \\
\hline \multicolumn{2}{|l|}{ Nodes (N stage) } \\
\hline NO & $1(6.7)$ \\
\hline N2 & $13(86.7)$ \\
\hline N3 & $1(6.7)$ \\
\hline \multicolumn{2}{|l|}{ Regimen used during CRT } \\
\hline Cisplatin-etoposide & $1(6.7)$ \\
\hline Carboplatin-paclitaxel & $12(80)$ \\
\hline Carboplatin-pemetrexed & $1(6.7)$ \\
\hline \multicolumn{2}{|c|}{ Best overall response to durvalumab } \\
\hline CR & $1(6.7)$ \\
\hline PR & $3(20)$ \\
\hline SD & $7(46.7)$ \\
\hline PD & $2(13.3)$ \\
\hline NE & $2(13.3)$ \\
\hline \multicolumn{2}{|l|}{ PD-L1 status (\%) } \\
\hline$<1$ & $2(13.3)$ \\
\hline $1-50$ & $9(60)$ \\
\hline$>50$ & $4(26.7)$ \\
\hline
\end{tabular}

Table 1 (continued)

\begin{tabular}{|l|l|}
\hline Demographic & $\boldsymbol{n ( \% )}$ \\
\hline Sites of new lesions & \\
\hline Lung & $2(13.3)$ \\
\hline Lymph node & $1(6.7)$ \\
\hline Liver & $1(6.7)$ \\
\hline Skeletal & $2(13.3)$ \\
\hline
\end{tabular}

Abbreviations: ALK, anaplastic lymphoma kinase; CEA, carcinoembryonic antigen; CMR, complete metabolic response; $C R$, complete response; CRT, chemoradiotherapy; EGFR, epidermal growth factor receptor; NE, not evaluable; PD, progressive disease; PD-LI, Programmed death-ligand 1; PET-CT, positron emission computed tomography; PR, partial response; ROS, v-ros UR2 sarcoma virus oncogene homolog 1 (avian); SD, stable disease; TNM, tumor node metastasis.

Table 2 Adverse effects of durvalumab

\begin{tabular}{|l|l|l|}
\hline Adverse event & Any grade, $\boldsymbol{n}(\%)$ & Grade $3 / 4, \boldsymbol{n}(\%)$ \\
\hline Any & $12(80)$ & $3(20)$ \\
\hline Arthritis & $2(13.3)$ & $1(6.7)$ \\
\hline Dermatitis & $2(13.3)$ & $1(6.7)$ \\
\hline Nephritis & $1(6.7)$ & $1(6.7)$ \\
\hline Pneumonitis & $1(6.7)$ & 0 \\
\hline Hypophysitis & $1(6.7)$ & 0 \\
\hline Hypothyroidism & $2(13.3)$ & 0 \\
\hline Cough & $2(13.3)$ & 0 \\
\hline Anemia & $1(6.7)$ & 0 \\
\hline
\end{tabular}

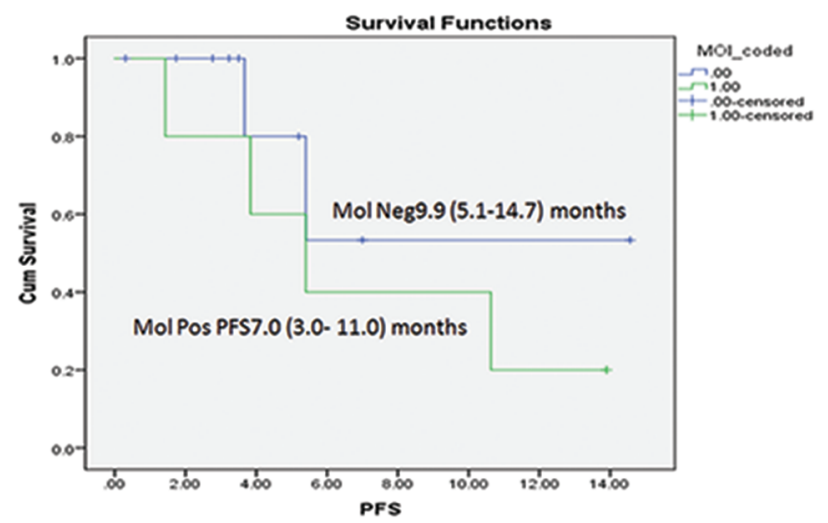

Fig. 2 Progression-free survival as per molecular status.

with a median follow-up of 9 months (1.4-14.5 months). All grade adverse effects were seen in 12 patients, wherein temporarily dosing was withheld in three patients due to nephritis $(n=1)$, arthritis $(n=1)$, and dermatitis $(n=1)$ (-Table 2). Of 15 evaluable patients, five patients were positive for any activating mutation and ten patients were mutation negative. Among those five mutation-positive patients, four had progressed (epidermal growth factor receptor-2, anaplastic lymphoma kinase-1, c-ros oncogene-1), while among 10 mutation-negative patients, two had progressed (-Fig. 2). None of the patients with PD-L1 $>50 \%(n=4)$ have 


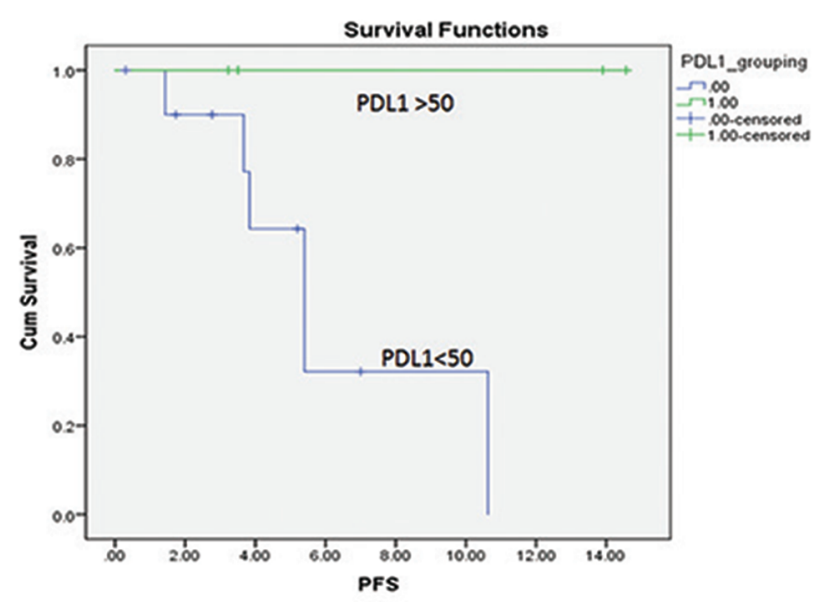

Fig. 3 Progression-free survival as per programmed death-ligand 1 status.

progressed at the last follow-up ( $>$ Fig. 3). This suggests that we need to develop these biomarkers further.

Durvalumab after chemoradiation can be safely administered in our population with efficacy similar to reported in the literature.
Funding

None.

\section{Conflicts of Interest}

Dr. Noronha reports grants from Amgen, grants from Sanofi India Ltd., grants from Dr. Reddy's Laboratories Inc., grants from Intas Pharmaceuticals, grants from Astra Zeneca Pharma India Ltd., outside the submitted work.

\section{References}

1 Antonia SJ, Villegas A, Daniel D, et al; PACIFIC Investigators. Durvalumab after chemoradiotherapy in stage III non-small-cell lung cancer. N Engl J Med 2017;377(20):1919-1929

2 Chakraborty S. A step-wise guide to performing survival analysis. Cancer Res Stat Treat 2018;1:41-5

3 Goldstraw P, Chansky K, Crowley J, et al; International Association for the Study of Lung Cancer Staging and Prognostic Factors Committee, Advisory Boards, and Participating Institutions; International Association for the Study of Lung Cancer Staging and Prognostic Factors Committee Advisory Boards and Participating Institutions. The IASLC lung cancer staging project: proposals for revision of the TNM stage groupings in the forthcoming (Eighth) edition of the TNM Classification for Lung Cancer.J Thorac Oncol 2016;11(1):39-51 